\title{
Associations between Variants in IL-33/ST2 Signaling Pathway Genes and Coronary Heart Disease Risk
}

\author{
Fangqin Wu ${ }^{1, \dagger}$, Mei’an He ${ }^{2, \dagger}$, Qiang Wen ${ }^{1}$, Wencai Zhang ${ }^{1}$, Jinhua Yang ${ }^{1}$, Xiaomin Zhang ${ }^{2}$, \\ Tangchun $\mathrm{Wu}^{2}$ and Longxian Cheng ${ }^{1, *}$
}

1 Department of Cardiology, Union Hospital, Tongji Medical College, Huazhong University of Science and Technology, 1277 Jiefang Dadao, Wuhan 430022, China; E-Mails: wufangqinnice@gmail.com (F.W.); tjwenqiang@126.com (Q.W.); zwc.8425@163.com (W.Z.); jinhua0371@163.com (J.Y.)

2 Institute of Occupational Medicine and the Ministry of Education, Key Lab of Environment and Health, School of Public Health, Tongji Medical College, Huazhong University of Science and Technology, 13 HangKong Road, Wuhan 430030, China; E-Mails: hemeian@hust.edu.cn (M.H.); mingxz117@hust.edu.cn (X.Z); wut@mails.tjmu.edu.cn (T.W.)

$\dagger$ These authors contributed equally to this work.

* Author to whom correspondence should be addressed; E-Mail: chenlongxian@medmail.com.cn; Tel.: +86-27-8572-6014; Fax: +86-27-8548-5621.

External Editor: Emil Alexov

Received: 25 October 2014; in revised form: 2 December 2014 / Accepted: 5 December 2014 / Published: 15 December 2014

\begin{abstract}
The IL-33/ST2 signaling pathway plays an important role in coronary artery disease (CHD); however, few studies have explored how variants in $I L-33 / S T 2$ genes influence CHD risk. Here, we examined the association between genetic variants in $I L-33$, ST2, and IL-1RACP of the $I L-33 / S T 2$ axis and the risk of CHD. We conducted a case-controlled study with $1146 \mathrm{CHD}$ cases and 1146 age- and sex-frequency-matched controls. Twenty-eight single nucleotide polymorphisms (SNPs) in IL-33, ST2, and $I L-1 R A c P$ were genotyped by Sequenom MassArray and TaqMan assay. Logistic regression was used to analyze these associations. The SNP rs4624606 in IL-1RAcP was nominally associated with $\mathrm{CHD}$ risk. The AA genotype was associated with a 1.85 -fold increased risk of CHD (95\% confidence interval $(\mathrm{CI})=1.01-3.36 ; p=0.045)$ compared to the TT genotype. Further analysis showed that AA carriers also had a higher risk of $\mathrm{CHD}$ than $\mathrm{TT}+\mathrm{TA}$ carriers (odds ratio $(\mathrm{OR})=1.85 ; 95 \% \mathrm{CI}=1.85-3.35$;
\end{abstract}


$p=0.043)$. However, no significant association was observed between variants in $I L-33 / S T 2$ genes and CHD risk. Further studies are needed to replicate our results in other ethnic groups with larger sample size.

Keywords: coronary artery disease; ST2; IL-33; IL-1RAcP; signaling pathway; gene

\section{Introduction}

Coronary heart disease (CHD) is a complex chronic inflammatory process mediated by the innate and acquired immune systems and involves pro- and anti-inflammatory cytokines [1]. Evidence indicates the interleukin 33/interleukin 1 receptor-like 1 (IL-33/ST2) axis participates in various fields of cardiovascular disease [2-7]. IL-33 is a member of the interleukin-1 family of cytokines, and ST2, which consists of a transmembrane ligand (ST2L), a soluble component (sST2), and ST2V, is the receptor for IL-33 [8]. IL-33 and ST2L form a heterodimeric receptor complex with IL-1R accessory protein (IL-1RAcP) $[9,10]$. By interacting with ST2L, IL-33 prevents cardiomyocyte apoptosis and attenuates myocardial fibrosis and myocyte hypertrophy [4]. In vivo, IL-33 significantly attenuates atherosclerotic cardiovascular disease in $\mathrm{ApoE}^{-/-}$mice on a high-fat diet via the induction of IL-5 and oxidized low-density lipoprotein antibodies. The IL-33 decoy receptor, sST2, alters the atheroprotective activity of IL-33 [2]. In contrast, other studies have reported that IL-33 promotes adhesion molecules and inflammatory activation in human endothelial cells and may, in such way, enhance the development of atherosclerotic lesions in the vessel wall $[11,12]$. The mechanisms of these contradictory effects of IL-33 are not yet completely understood yet. Clinically, IL-33 serum levels were elevated in patients with heart failure and associated with coronary in-stent restenosis and mortality in patients with ST elevation myocardial infarction [13-16]. Furthermore, sST2 has been demonstrated as a strong prognostic biomarker in patients with heart failure and myocardial infarction [3,5,17-19].

Despite powerful biological and prognostic data describing the role of IL-33/ST2 signaling in the development of CHD, there is little information regarding the significance of $I L-33 / S T 2$ genetic variants in CHD. Recently, Tsapaki et al. revealed that two polymorphisms in the distal promoter region of $S T 2$ were associated with susceptibility to severe CHD [20]. In addition, polymorphisms in genes involved in the IL-33/ST2 pathway have been associated with several immune and inflammatory diseases [21-33].

Therefore, considering the role of inflammation in CHD, we hypothesized that polymorphisms in $I L-33 / S T 2$ might be associated with CHD risk. To test this hypothesis, we performed a genetic association analysis of $I L-33 / S T 2$ and CHD risk in a case-control study of the Han Chinese population.

\section{Results and Discussion}

\subsection{Characteristics of the Case and Control Subjects}

The general characteristics of the case-control study population are presented in Table 1 . Age and sex were similar for case and control subjects. Traditional CHD risk factors, such as body mass index (BMI) and fasting blood glucose (FBG), were significantly higher in CHD cases than 
in control subjects. CHD cases were more likely have a history of hypertension, diabetes mellitus (DM), and a family history of CHD. Total cholesterol (TC) levels were significantly lower in the cases than in the controls, possibly due to the use of cholesterol-lowering medications in this population.

Table 1. General characteristics of the study population.

\begin{tabular}{cccc}
\hline Variables & Cases $(\boldsymbol{n}=\mathbf{1 1 4 6})$ & Controls $(\boldsymbol{n}=\mathbf{1 1 4 6})$ & $\boldsymbol{p}$ Value \\
\hline Sex, m/f $(\%)$ & $901 / 245(78.6 / 21.4)$ & $891 / 255(77.7 / 22.3)$ & 0.613 \\
\hline Age, years & $60.5 \pm 11.3$ & $60.0 \pm 10.3$ & 0.23 \\
\hline Blood pressure, $\mathrm{mmHg}$ & & & \\
Systolic & $133.6 \pm 29.0$ & $136.0 \pm 25.3$ & 0.034 \\
Diastolic & $82.0 \pm 11.3$ & $82.9 \pm 15.2$ & 0.11 \\
\hline Body mass index, $\mathrm{kg} / \mathrm{m}^{2}$ & $23.7 \pm 3.1$ & $24.4 \pm 3.3$ & $<0.01$ \\
\hline Fasting glucose, $\mathrm{mmol} / \mathrm{L}$ & $5.6 \pm 2.2$ & $6.2 \pm 3.0$ & $<0.01$ \\
\hline Total cholesterol, mmol/L & $4.35 \pm 1.10$ & $4.68 \pm 0.92$ & $<0.01$ \\
\hline Triglyceride, mmol/L & $1.61 \pm 1.30$ & $1.67 \pm 1.38$ & 0.283 \\
\hline Smoking, no/yes (\%) & $686 / 460(59.9 / 40.1)$ & $774 / 369(67.7 / 32.3)$ & $<0.01$ \\
\hline Alcohol drinking, no/yes (\%) & $776 / 365(68.0 / 32.0)$ & $822 / 317(72.2 / 27.8)$ & $<0.01$ \\
\hline Past history & & & \\
Hypertension, no/yes & $784 / 361(68.5 / 31.5)$ & $351 / 790(30.8 / 69.2)$ & $<0.01$ \\
Diabetics, no/yes & $1080 / 65(94.3 / 5.7)$ & $824 / 314(72.4 / 27.6)$ & $<0.01$ \\
Family history of CHD, no/yes (\%) & $1133 / 10(99.1 / 0.9)$ & $947 / 158(85.7 / 14.3)$ & $<0.01$ \\
\hline
\end{tabular}

Variables are presented as the mean $\pm \mathrm{SD}$ or percentage. $p$-Values were calculated; using independent-sample $t$-tests or Chi-square tests.

\subsection{Associations between Interleukin 33 (IL-33)/Interleukin 1 Receptor-Like 1 (ST2)/IL-1R Accessory} Protein (IL-1RAcP) Variants and Coronary Heart Disease (CHD) Risk

All the SNPs conformed to Hardy-Weinberg equilibrium (HWE) $(p>0.001)$ except rs1157505, which significantly deviated from HWE in both control subjects and CHD cases $(p<0.001)$. The minor allele frequency (MAF) for -27307T/A and -27614C/A were 0, and these alleles have not previously been found in the Chinese Han population according to the HapMap database. Thus, 25 SNPs were selected for further analysis. To analyze the associations between these SNPs and CHD risk, we compared differences in the genotype distribution of each polymorphism between case and control subjects and analyzed the genotypes as dominant/recessive models. As shown in Table 2, homozygous rs4624606 variants (AA) had a significantly increased risk of CHD (OR = 1.85; 95\% CI $=1.01-3.36 ; p=0.045)$ compared to subjects with homozygous wild-type alleles (TT) after adjustment for conventional CHD risk factors, such as age, sex, smoking, drinking, BMI, triglyceride (TG), hypertension, DM, and family history of CHD. The SNP rs4624606 was also associated with a significantly increased risk of CHD in a recessive model (AA vs. $(\mathrm{TT}+\mathrm{TA})$ : $\mathrm{OR}=1.85$; $95 \%$ CI $=1.02-3.35 ; p=0.043$, Table 2 ). This study had greater than $90 \%$ power to detect the associations between rs4624606 and CHD risk $>1.85$ at a 0.05 significance level under both additive and recessive models. However, $p$-values for rs4624606 failed to reach significance after Bonferroni correction $(p>0.002)$. There was no significant association between the remaining 24 SNPs and CHD risk in the Chinese population $(p>0.05)$. 
Table 2. Genotype frequencies of 25 SNPs and their association with coronary heart disease (CHD) risk in the Chinese population.

\begin{tabular}{|c|c|c|c|c|c|c|c|c|c|c|}
\hline \multirow{2}{*}{ SNPs } & \multirow{2}{*}{ Case $^{a}$} & \multirow{2}{*}{ Control $^{a}$} & \multicolumn{2}{|c|}{ Heterozygote $^{b}$} & \multicolumn{2}{|c|}{ Variant Homozygote $^{\text {b }}$} & \multicolumn{2}{|c|}{ Dominant Model $^{\mathrm{c}}$} & \multicolumn{2}{|c|}{ Recessive Model $^{\mathrm{d}}$} \\
\hline & & & OR $(95 \% \mathrm{CI})^{\mathrm{e}}$ & $p^{\mathrm{e}}$ & OR $\left(95 \%\right.$ CI) ${ }^{\mathrm{e}}$ & $p^{\mathrm{e}}$ & OR $(95 \% \text { CI })^{\text {e }}$ & $p^{\mathrm{e}}$ & OR $\left(95 \%\right.$ CI) ${ }^{\mathrm{e}}$ & $p^{\mathrm{e}}$ \\
\hline \multicolumn{11}{|l|}{ IL33 } \\
\hline rs1929992 & $353 / 538 / 217$ & $369 / 527 / 210$ & $1.04(0.82-1.32)$ & 0.733 & $1.11(0.83-1.49)$ & 0.485 & $1.06(0.85-1.32)$ & 0.594 & $1.08(0.84-1.41)$ & 0.542 \\
\hline rs 10975520 & $327 / 554 / 246$ & $335 / 539 / 234$ & $1.00(0.79-1.27)$ & 0.987 & $1.08(0.81-1.44)$ & 0.618 & $1.02(0.82-1.28)$ & 0.83 & $1.07(0.84-1.38)$ & 0.570 \\
\hline rs11792633 & $361 / 552 / 222$ & $363 / 530 / 211$ & $1.01(0.80-1.28)$ & 0.912 & $1.09(0.81-1.45)$ & 0.581 & $1.03(0.83-1.29)$ & 0.762 & $1.08(0.83-1.39)$ & 0.571 \\
\hline rs1624159 & $1010 / 94 / 3$ & $1020 / 91 / 6$ & $0.88(0.61-1.28)$ & 0.513 & $2.83(0.58-13.9)$ & 0.199 & $0.93(0.65-1.35)$ & 0.709 & $2.86(0.58-14.04)$ & 0.195 \\
\hline \multicolumn{11}{|l|}{$S T 2$} \\
\hline rs3755278 & $974 / 86 / 3$ & $1045 / 89 / 4$ & $1.02(0.70-1.49)$ & 0.928 & $3.44(0.53-22.19)$ & 0.193 & $1.06(0.73-1.54)$ & 0.743 & $3.44(0.53-22.16)$ & 0.194 \\
\hline rs3821204 & $457 / 512 / 157$ & $452 / 522 / 134$ & $0.94(0.76-1.18)$ & 0.612 & $1.26(0.90-1.75)$ & 0.178 & $1.00(0.81-1.24)$ & 0.972 & $1.30(0.95-1.77)$ & 0.102 \\
\hline rs13431828 & $925 / 194 / 15$ & $932 / 166 / 10$ & $1.16(0.88-1.54)$ & 0.284 & $0.91(0.35-2.38)$ & 0.843 & $1.15(0.87-1.50)$ & 0.326 & $0.89(0.34-2.32)$ & 0.805 \\
\hline rs 10206753 & $839 / 272 / 26$ & $832 / 252 / 24$ & $1.07(0.84-1.37)$ & 0.562 & $0.97(0.49-1.93)$ & 0.939 & $1.06(0.84-1.34)$ & 0.598 & $0.96(0.48-1.89)$ & 0.898 \\
\hline rs1041973 & $845 / 248 / 41$ & $844 / 234 / 30$ & $1.00(0.78-1.29)$ & 0.977 & $1.41(0.79-2.49)$ & 0.243 & $1.05(0.83-1.33)$ & 0.681 & $1.40(0.80-2.48)$ & 0.242 \\
\hline rs12999364 & $409 / 536 / 185$ & $407 / 527 / 174$ & $0.99(0.79-1.24)$ & 0.908 & $1.13(0.83-1.55)$ & 0.436 & $1.02(0.82-1.26)$ & 0.854 & $1.14(0.86-1.51)$ & 0.363 \\
\hline rs6543116 & $337 / 571 / 216$ & $326 / 537 / 245$ & $1.02(0.81-1.30)$ & 0.845 & $0.82(0.61-1.10)$ & 0.189 & $0.96(0.77-1.21)$ & 0.735 & $0.81(0.62-1.04)$ & 0.101 \\
\hline rs951774 & $660 / 413 / 58$ & $630 / 408 / 70$ & $0.91(0.73-1.13)$ & 0.377 & $0.91(0.57-1.45)$ & 0.683 & $0.91(0.74-1.12)$ & 0.358 & $0.94(0.60-1.49)$ & 0.8 \\
\hline rs10515922 & $843 / 263 / 26$ & $833 / 247 / 28$ & $1.00(0.78-1.27)$ & 0.976 & $1.13(0.55-2.29)$ & 0.745 & $1.01(0.79-1.28)$ & 0.955 & $1.13(0.55-2.29)$ & 0.742 \\
\hline rs13006559 & $1063 / 77 / 2$ & $1046 / 59 / 3$ & $1.24(0.80-1.94)$ & 0.34 & $1.37(0.12-15.25)$ & 0.798 & $1.25(0.80-1.93)$ & 0.326 & $1.36(0.12-15.10)$ & 0.804 \\
\hline \multicolumn{11}{|l|}{$I L-1 R A c P$} \\
\hline rs1015704 & $725 / 359 / 46$ & $686 / 381 / 41$ & $0.89(0.71-1.11)$ & 0.295 & $1.02(0.59-1.78)$ & 0.935 & $0.90(0.73-1.12)$ & 0.34 & $1.07(0.62-1.84)$ & 0.819 \\
\hline rs9817203 & $515 / 493 / 122$ & $506 / 489 / 113$ & $1.05(0.84-1.30)$ & 0.685 & $1.24(0.87-1.77)$ & 0.228 & $1.08(0.88-1.33)$ & 0.461 & $1.22(0.87-1.70)$ & 0.255 \\
\hline rs1559018 & $300 / 549 / 279$ & $276 / 569 / 262$ & $0.97(0.76-1.25)$ & 0.825 & $1.14(0.85-1.53)$ & 0.378 & $1.02(0.81-1.30)$ & 0.846 & $1.16(0.91-1.48)$ & 0.223 \\
\hline rs3773986 & $861 / 245 / 19$ & $844 / 250 / 14$ & $1.01(0.79-1.29)$ & 0.936 & $1.23(0.52-2.91)$ & 0.644 & $1.02(0.80-1.30)$ & 0.86 & $1.22(0.52-2.90)$ & 0.647 \\
\hline rs6765375 & $736 / 350 / 45$ & $699 / 375 / 34$ & $0.89(0.71-1.11)$ & 0.301 & $1.18(0.66-2.11)$ & 0.576 & $0.91(0.74-1.13)$ & 0.408 & $1.23(0.69-2.18)$ & 0.486 \\
\hline rs4624606 & $734 / 338 / 46$ & $731 / 351 / 26$ & $0.99(0.79-1.25)$ & 0.962 & $1.85(1.01-3.36)$ & 0.045 & $1.05(0.85-1.31)$ & 0.636 & 1.85 (1.02-3.35) & 0.043 \\
\hline rs16865597 & $877 / 204 / 12$ & $854 / 223 / 17$ & $1.02(0.78-1.32)$ & 0.892 & $1.19(0.45-3.12)$ & 0.728 & $1.03(0.79-1.33)$ & 0.837 & $1.18(0.45-3.11)$ & 0.733 \\
\hline rs 4687150 & $559 / 434 / 105$ & $543 / 433 / 110$ & $0.92(0.74-1.15)$ & 0.459 & $0.90(0.62-1.30)$ & 0.58 & $0.92(0.74-1.13)$ & 0.412 & $0.94(0.66-1.33)$ & 0.712 \\
\hline
\end{tabular}


Table 2. Cont.

\begin{tabular}{|c|c|c|c|c|c|c|c|c|c|c|}
\hline \multirow{2}{*}{ SNPs } & \multirow{2}{*}{ Case $^{a}$} & \multirow{2}{*}{ Control $^{a}$} & \multicolumn{2}{|c|}{ Heterozygote $^{b}$} & \multicolumn{2}{|c|}{ Variant Homozygote $^{\text {b }}$} & \multicolumn{2}{|c|}{ Dominant Model $^{c}$} & \multicolumn{2}{|c|}{ Recessive Model $^{\mathrm{d}}$} \\
\hline & & & OR $(95 \% \mathrm{CI})^{\mathrm{e}}$ & $p^{\mathrm{e}}$ & OR $(95 \% \mathrm{CI})^{\mathrm{e}}$ & $p^{\mathrm{e}}$ & OR $(95 \% \mathrm{CI})^{\mathrm{e}}$ & $p^{\mathrm{e}}$ & OR $(95 \% \text { CI })^{e}$ & $p^{\mathrm{e}}$ \\
\hline rs3773958 & $380 / 548 / 200$ & $368 / 534 / 206$ & 0.97 & 0.779 & & 0.729 & $0)$ & 0.728 & .26) & 0.806 \\
\hline rs3773981 & $695 / 330 / 57$ & $726 / 336 / 42$ & $0.94(0.75-1.18)$ & 0.59 & 1.09( & 0.751 & $0.96(0.7$ & 0.692 & 1.11 & 0.689 \\
\hline rs6444435 & $638 / 340 / 65$ & $691 / 363 / 51$ & $0.97(0.77-1.22)$ & 0.797 & $1.39(0.87-2.23)$ & 0.168 & $1.02(0.82-1.27)$ & 0.843 & $1.41(0.88-2.24)$ & 0.150 \\
\hline
\end{tabular}

a Wild-type homozygote/heterozygote/variant homozygote; ${ }^{\mathrm{b}}$ The reference group comprised subjects homozygous for the wild-type allele; ${ }^{\mathrm{c}}$ Dominant model (wild-type homozygote vs. heterozygote + variant homozygote); ${ }^{\mathrm{d}}$ Recessive model (wild-type homozygote + heterozygote vs. variant homozygote); ${ }^{\mathrm{e}}$ Data were calculated by unconditional logistic regression, adjusted for age, sex, smoking, drinking, BMI, TG, hypertension, DM, and family history of CHD. Numbers in bold mean the SNP rs 4624606 was also associated with a significantly increased risk of CHD in a recessive model (AA vs. (TT + TA): OR $=1.85 ; 95 \% \mathrm{CI}=1.02-3.35 ; p=0.043$, Table 2). 


\subsection{Association Analyses for Stratified Traditional Risk Factors}

To evaluate whether traditional risk factors influenced the effects of genetic variants on CHD risk, we conducted stratification analysis for rs4624606 by sex, smoking, drinking, BMI, hypertension, and diabetes and examined the interactions between this SNP and traditional risk factors for CHD risk. As shown in Table 3, rs4624606 was associated with higher risk in hypertensive subjects (AA vs. TT: $\mathrm{OR}=2.77,95 \% \mathrm{CI}=1.01-7.57$; AA vs. $(\mathrm{TT}+\mathrm{TA})$ : $\mathrm{OR}=2.91,95 \% \mathrm{CI}=1.07-7.93)$. However, no significant interactions were observed between rs4624606 and sex, smoking, drinking, BMI, hypertension, or diabetes (all $p>0.05$ ).

Table 3. Stratification analysis for the association between rs4624606 and the risk of CHD.

\begin{tabular}{|c|c|c|c|c|c|c|c|}
\hline \multicolumn{8}{|c|}{ rs4624606 OR $(95 \% \text { CI })^{a}$} \\
\hline Variables & TT & TA & $\mathbf{A A}$ & $p^{b}$ & TT + TA & $\mathbf{A A}$ & $p^{b}$ \\
\hline \multicolumn{8}{|l|}{ Sex } \\
\hline Male & 1.00 & $0.95(0.74-1.22)$ & $1.70(0.89-3.23)$ & 0.515 & 1.00 & $1.72(0.91-3.27)$ & \multirow{2}{*}{0.826} \\
\hline Female & 1.00 & $1.24(0.72-2.12)$ & $1.37(0.22-8.69)$ & & 1.00 & $1.26(0.20-7.93)$ & \\
\hline \multicolumn{8}{|l|}{ Smoke status } \\
\hline Smokers & 1.00 & $0.98(0.67-1.45)$ & $1.68(0.58-4.88)$ & 0.820 & 1.00 & $1.69(0.59-4.87)$ & \multirow{2}{*}{0.951} \\
\hline Nonsmokers & 1.00 & $0.95(0.72-1.26)$ & $1.82(0.87-3.80)$ & & 1.00 & $1.85(0.89-3.84)$ & \\
\hline \multicolumn{8}{|l|}{ Drink } \\
\hline Drinkers & 1.00 & $0.92(0.60-1.39)$ & $1.99(0.61-6.43)$ & 0.974 & 1.00 & $1.74(0.86-3.53)$ & \multirow{2}{*}{0.793} \\
\hline Nondrinkers & 1.00 & $1.00(0.76-1.30)$ & $1.74(0.85-3.55)$ & & 1.00 & $2.04(0.64-6.56)$ & \\
\hline \multicolumn{8}{|l|}{ BMI, $\mathrm{kg} / \mathrm{m}^{2}$} \\
\hline$<25$ & 1.00 & $1.08(0.82-1.43)$ & $1.55(0.70-3.47)$ & 0.204 & 1.00 & $1.52(0.68-3.38)$ & \multirow{2}{*}{0.365} \\
\hline$\geq 25$ & 1.00 & $0.85(0.58-1.24)$ & $2.24(0.88-5.75)$ & & 1.00 & $2.33(0.92-5.91)$ & \\
\hline \multicolumn{8}{|l|}{ Hypertension } \\
\hline No & 1.00 & $1.22(0.89-1.68)$ & $1.32(0.57-3.05)$ & 0.491 & 1.00 & $1.24(0.54-2.84)$ & \multirow{2}{*}{0.246} \\
\hline Yes & 1.00 & $0.85(0.62-1.17)$ & $2.77(1.01-7.57)^{\mathrm{c}}$ & & 1.00 & $2.91(1.07-7.93)^{c}$ & \\
\hline \multicolumn{8}{|l|}{ Diabetes } \\
\hline No & 1.00 & $1.02(0.80-1.29)$ & $1.85(0.99-3.44)$ & 0.626 & 1.00 & $1.84(0.99-3.40)$ & \multirow{2}{*}{0.941} \\
\hline Yes & 1.00 & $0.87(0.42-1.79)$ & $1.72(0.17-17.27)$ & & 1.00 & $1.78(0.18-17.72)$ & \\
\hline
\end{tabular}

\section{Discussion}

In this case-control study, we investigated the associations of 28 polymorphisms in IL-33/ST2 signaling pathway genes with the risk of CHD. Our results showed that subjects with the rs4624606 AA genotype in the $I L-1 R A c P$ gene had an increased risk of CHD. Especially among hypertensive subjects, the genotype AA was strongly associated with a higher risk of CHD. It is possible that hypertension may exacerbate the influence of genetic factors. No variants in $I L-33$ or ST2 were associated with CHD risk. Moreover, no interactions were observed between these SNPs and CHD traditional risk factors. 
Numerous in vitro and in vivo model studies have found that activation of the IL-33/ST2 signaling pathway can significantly attenuate the severity of CHD [4]. IL-33 appears to provide anti-atherosclerotic benefits in CHD. Furthermore, the SST2 isoform acts as a decoy receptor to reduce IL-33 signaling through the ST2L receptor and is a significant predictor of mortality in patients with several cardiovascular disorders [6]. To further explore the role of the $I L-33$ gene in the pathogenesis of CHD, we tested the association between $I L-33$ polymorphisms and CHD; however, no significant associations were found, nor were there significant interactions between these SNPs and traditional CHD risk factors.

The ST2 gene is located in chromosome 2q12 and contains 11 exons, a proximal promoter, and a distal promoter [24]. Many researchers have reported that rs6543116 (-26999G/A) in the distal promoter region of $S T 2$ is associated with increased risk for atopic dermatitis and asthma [32,34]. Recently, Tsapaki et al. reported that -27307T/A and -27614C/A polymorphisms in the distal promoter region of ST2 influence susceptibility to severe CHD [20]. Based on these results, we hypothesized that SNPs in the distal promoter region of ST2 might be associated with CHD risk. In this study, we replicated these SNPs (rs6543116, -27307T/A, -27614C/A) and examined another three SNPs (rs951774, rs10515922, and 13006559) in the distal promoter region, which were selected by extending $30 \mathrm{~kb}$ into the $5^{\prime}$ end of $S T 2$. We also analyzed the tagSNPs in the $S T 2$ gene to explore the genetic role of ST2 in the pathogenesis of CHD. However, we failed to show an association between these SNPs and CHD. One possibility for this discrepancy may be due to ethnic and phenotypic differences and disparate environmental effects between countries.

IL-1RAcP is a member of the $I L-33 / S T 2$ axis receptor complex and has been reported to play an important role in CHD [9]. Soluble IL-1RAcP interacts with the sST2-IL-33 complex to increase inhibition of IL-33 signaling. The $I L-1 R A c P$ gene is located on chromosome $3 \mathrm{q} 28$. Genetic variants in $I L-1 R A c P$ have been associated with prostate cancer, Kawasaki disease, and persistent hepatitis B virus [23,30,33]; however, the role of $I L-1 R A c P$ polymorphisms in CHD has never been investigated. In this study, we selected 11 tagSNPs and found that rs4624606 was associated with increased risk of CHD. Ramkumar et al. also reported that rs4624606 was associated with higher amniotic fluid IL-1 $\beta$ concentrations [26]. The SNP rs4624606 is located in the intron of $I L-1 R A c P$. However, no functional studies have been performed to determine the characteristics of this SNP. Further research is required to understand the functions of variants associated with CHD.

Our study has several limitations. First, like other case-control studies, a possible selection bias (inclusion of surviving CHD patients) may exist. Second, not all controls had coronary angiography, introducing the possibility of false-negative cases. However, our controls had normal electrocardiography (ECG), no clinical symptoms, and no history of CHD before enrollment; additionally, false negatives are likely to be rare.

\section{Experimental Section}

\subsection{Study Population}

The sample population included 1146 patients and 1146 age- and sex-frequency-matched controls. CHD patients were recruited from three hospitals (Union Hospital, Tongji Hospital, and Wugang 
Hospital) in Wuhan, China [35,36]. CHD was diagnosed as angiographically demonstrated stenoses $(\geq 50 \%)$ in a major or main branch of the coronary artery [37]. The control subjects, residing in the same communities as the patients, were determined to be free of CHD and peripheral atherosclerotic arterial disease by medical history, clinical examinations, and ECG. All subjects completed an Inter-Heart questionnaire and were interviewed about their demographic data, medical history, history of disease, family history of cardiovascular disease, and lifestyle habits (including smoking and alcohol consumption) by trained interviewers. The study was approved by the Ethics Committee of Tongji Medical College (project identification code: S073, 21 February 2011), and all participants provided written informed consent.

\subsection{Selection of Polymorphisms}

TagSNPs were selected based on the HapMap phase I \& II database (http://www.hapmap.org, CHB and JPT as the reference set). According to the criteria of $r^{2} \geq 0.8$ and minor allele frequency $(\mathrm{MAF}) \geq 0.05$, we extended $2000 \mathrm{bp}$ into the $5^{\prime}$ and $3^{\prime}$ ends of $I L-33$ and $I L-1 R A c P$. To cover the distal promoter region of $S T 2$, we extended $30 \mathrm{~kb}$ into the $5^{\prime}$ and $2000 \mathrm{bp}$ into the $3^{\prime}$ end of ST2. Thus, we selected 18 tagSNPs in the three genes. We selected another 10 SNPs from previous reports in CHD (-27307T/A, -27614C/A) and other diseases, including Alzheimer's disease, asthma, and atopic dermatitis [20,21,32,38]. In total, we selected and genotyped 28 SNPs (Table 4).

Table 4. SNP locations and allele frequencies.

\begin{tabular}{cccccc}
\hline SNP & Gene & Location & Genotype & MAF * & HWE $\boldsymbol{p}{ }^{*}$ \\
\hline rs1929992 & $I L 33$ & Intron & $\mathrm{A} / \mathrm{G}$ & 0.489 & 0.655 \\
rs10975520 & $I L 33$ & Intron & $\mathrm{G} / \mathrm{C}$ & 0.488 & 1 \\
rs11792633 & $I L 33$ & Intron & $\mathrm{T} / \mathrm{C}$ & 0.433 & - \\
rs1157505 & $I L 33$ & Intron & $\mathrm{G} / \mathrm{C}$ & 0.225 & - \\
rs1624159 & $I L 33$ & Between genes & $\mathrm{A} / \mathrm{G}$ & 0.06 & 0.02 \\
rs3755278 & $S T 2$ & intron & $\mathrm{A} / \mathrm{G}$ & 0.067 & 1 \\
rs3821204 & $S T 2$ & 3'-Flanking region & $\mathrm{C} / \mathrm{G}$ & 0.358 & 0.403 \\
rs13431828 & $S T 2$ & 5'-Flanking region & $\mathrm{T} / \mathrm{C}$ & 0.089 & 1 \\
rs10206753 & $S T 2$ & Exon & $\mathrm{C} / \mathrm{T}$ & 0.133 & 1 \\
rs1041973 & $S T 2$ & Exon & $\mathrm{A} / \mathrm{C}$ & 0.156 & 0.527 \\
rs12999364 & $S T 2$ & Between genes & $\mathrm{T} / \mathrm{C}$ & 0.45 & - \\
rs6543116 & $S T 2$ & Distal promoter & $\mathrm{A} / \mathrm{G}$ & 0.367 & - \\
rs951774 & $S T 2$ & Distal promoter & $\mathrm{A} / \mathrm{C}$ & 0.233 & 0.251 \\
rs10515922 & $S T 2$ & Distal promoter & $\mathrm{C} / \mathrm{T}$ & 0.151 & 1 \\
rs13006559 & $S T 2$ & Distal promoter & $\mathrm{T} / \mathrm{C}$ & 0.07 & 1 \\
$-27307 T / \mathrm{A}$ & $S T 2$ & Distal promoter & $\mathrm{T} / \mathrm{A}$ & - & - \\
$-27614 \mathrm{C} / \mathrm{A}$ & $S T 2$ & Distal promoter & $\mathrm{C} / \mathrm{A}$ & - & - \\
rs1015704 & $I L-1 R A C P$ & intron & $\mathrm{G} / \mathrm{A}$ & 0.222 & 0.294 \\
rs9817203 & $I L-1 R A c P$ & intron & $\mathrm{T} / \mathrm{C}$ & 0.395 & 0.439 \\
rs1559018 & $I L-1 R A c P$ & intron & $\mathrm{G} / \mathrm{A}$ & 0.488 & 0.479 \\
rs3773986 & $I L-1 R A c P$ & intron & $\mathrm{T} / \mathrm{C}$ & 0.067 & 1 \\
rs6765375 & $I L-1 R A c P$ & intron & $\mathrm{C} / \mathrm{A}$ & 0.233 & 1 \\
rs4624606 & $I L-1 R A c P$ & intron & $\mathrm{A} / \mathrm{T}$ & 0.213 & 0.294 \\
\hline
\end{tabular}


Table 4. Cont.

\begin{tabular}{cccccc}
\hline SNP & Gene & Location & Genotype & MAF * & HWE $\boldsymbol{p} *$ \\
\hline rs16865597 & $I L-1 R A C P$ & intron & $\mathrm{C} / \mathrm{T}$ & 0.159 & 0.273 \\
rs4687150 & $I L-1 R A c P$ & intron & $\mathrm{T} / \mathrm{C}$ & 0.341 & 0.403 \\
rs3773958 & $I L-1 R A c P$ & intron & $\mathrm{G} / \mathrm{T}$ & 0.419 & 0.752 \\
rs3773981 & $I L-1 R A c P$ & intron & $\mathrm{C} / \mathrm{A}$ & 0.182 & 0.584 \\
rs6444435 & $I L-1 R A c P$ & intron & $\mathrm{A} / \mathrm{G}$ & 0.251 & 0.233 \\
\hline
\end{tabular}

* Data from the NCBI; - Data were not found in http://www.ncbi.nlm.nih.gov/snp/.

\subsection{DNA Isolation and Genotyping}

Fasting venous blood was collected from the peripheral vein, and genomic DNA was extracted with a Puregene kit (Gentra Systems Inc., Minneapolis, MN, USA). Twenty-five SNPs were genotyped using the Sequenom MassArray system (Sequenom Inc., San Diego, CA, USA). The remaining rs3755278, rs6444435, and rs1157505 SNPs were genotyped by TaqMan SNP allelic discrimination (Applied Biosystems, Foster City, CA, USA). TaqMan data collection and analysis were performed with SDS 2.2.1. Thus, 28 SNPs were successfully genotyped with a successful call rate of greater than $95 \%$, with the exception of rs 6444435 , for which the call rate was $93.7 \%$.

\subsection{Biological Variable Determination}

FBG, TC, and TG were assayed by standard laboratory procedures in the clinical laboratory department at Union Hospital.

\subsection{Statistical Analysis}

Continuous variables are expressed as means \pm standard deviation (SD). The normal distribution of data was verified by the Kolmogorov-Smirnov normality test. Continuous data with a normal distribution were compared by Student's $t$-test, and those with unequal variance or without a normal distribution were analyzed by Mann-Whitney rank-sum tests. Chi-square tests were used to compare categorical variables and the HWE of the polymorphisms. Unconditional logistic regression analysis was used to estimate the associations between SNPs and CHD risk after adjustment for age, sex, smoking, drinking, body mass index (BMI), TG, hypertension, DM, and family history of CHD by odds ratios (ORs) and 95\% confidence intervals (CIs). The interactions of covariates with SNP genotypes were tested using the Wald test in unconditional logistic regression models. The significance of multiplicative interactions between SNPs and covariates was determined by the likelihood ratio test using the logistic regression model. Power calculations were performed using the QUANTO software program (Version 1.2.3) [39]. All other statistical analyses were carried out with the statistical analysis software package SPSS 12.0 (SPSS Inc., Chicago, IL, USA). Differences or associations with $p$-values of less than 0.05 were considered significant. 


\section{Conclusions}

In conclusion, we found that the SNP rs4624606 within the IL-1RAcP locus was nominally associated with CHD susceptibility. Further studies in other independent populations with large sample sizes are required to validate these findings.

\section{Acknowledgments}

This research was supported by a grant from the National Natural Scientific Foundation of China (Grant No. 81172750).

\section{Author Contributions}

Conceived and designed the experiments: Longxian Cheng, Fangqin Wu, Mei'an He; Performed the experiments: Fangqin Wu, Qiang Wen, Wencai Zhang, Jinhua Yang; Analyzed the data: Fangqin Wu, Mei'an He; Contributed reagents/materials/analysis tools: Xiaomin Zhang, Tangchun Wu, Longxian Cheng; Wrote the paper: Fangqin Wu, Mei’an He, Longxian Cheng.

\section{Conflicts of Interest}

The authors declare no conflict of interest.

\section{References}

1. Profumo, E.; Buttari, B.; Saso, L.; Capoano, R.; Salvati, B.; Rigano, R. T lymphocyte autoreactivity in inflammatory mechanisms regulating atherosclerosis. Sci. World J. 2012, 2012, 157534.

2. Miller, A.M.; Xu, D.; Asquith, D.L.; Denby, L.; Li, Y.; Sattar, N.; Baker, A.H.; McInnes, I.B.; Liew, F.Y. IL-33 reduces the development of atherosclerosis. J. Exp. Med. 2008, 205, 339-346.

3. Weinberg, E.O.; Shimpo, M.; Hurwitz, S.; Tominaga, S.; Rouleau, J.L.; Lee, R.T. Identification of serum soluble ST2 receptor as a novel heart failure biomarker. Circulation 2003, 107, 721-726.

4. Liew, F.Y.; Pitman, N.I.; McInnes, I.B. Disease-associated functions of IL-33: The new kid in the IL-1 family. Nat. Rev. Immunol. 2010, 10, 103-110.

5. Dhillon, O.S.; Narayan, H.K.; Quinn, P.A.; Squire, I.B.; Davies, J.E.; Ng, L.L. Interleukin 33 and ST2 in non-ST-elevation myocardial infarction: Comparison with global registry of acute coronary events risk scoring and NT-proBNP. Am. Heart J. 2011, 161, 1163-1170.

6. Miller, A.M.; Liew, F.Y. The IL-33/ST2 pathway-A new therapeutic target in cardiovascular disease. Pharmacol. Ther. 2011, 131, 179-186.

7. Milovanovic, M.; Volarevic, V.; Radosavljevic, G.; Jovanovic, I.; Pejnovic, N.; Arsenijevic, N.; Lukic, M.L. IL-33/ST2 axis in inflammation and immunopathology. Immunol. Res. 2012, 52, 89-99.

8. Schmitz, J.; Owyang, A.; Oldham, E.; Song, Y.; Murphy, E.; McClanahan, T.K.; Zurawski, G.; Moshrefi, M.; Qin, J.; Li, X.; et al. IL-33, an interleukin-1-like cytokine that signals via the IL-1 receptor-related protein ST2 and induces T helper type 2-associated cytokines. Immunity 2005, 23, 479-490. 
9. Chackerian, A.A.; Oldham, E.R.; Murphy, E.E.; Schmitz, J.; Pflanz, S.; Kastelein, R.A. IL-1 receptor accessory protein and ST2 comprise the IL-33 receptor complex. J. Immunol. 2007, 179, 2551-2555.

10. Liu, X.; Hammel, M.; He, Y.; Tainer, J.A.; Jeng, U.S.; Zhang, L.; Wang, S.; Wang, X. Structural insights into the interaction of IL-33 with its receptors. Proc. Natl. Acad. Sci. USA 2013, 110, 14918-14923.

11. Choi, Y.S.; Choi, H.J.; Min, J.K.; Pyun, B.J.; Maeng, Y.S.; Park, H.; Kim, J.; Kim, Y.M.; Kwon, Y.G. Interleukin-33 induces angiogenesis and vascular permeability through ST2/TRAF6-mediated endothelial nitric oxide production. Blood 2009, 114, 3117-3126.

12. Demyanets, S.; Konya, V.; Kastl, S.P.; Kaun, C.; Rauscher, S.; Niessner, A.; Pentz, R.; Pfaffenberger, S.; Rychli, K.; Lemberger, C.E.; et al. Interleukin-33 induces expression of adhesion molecules and inflammatory activation in human endothelial cells and in human atherosclerotic plaques. Arterioscler. Thromb. Vasc. Biol. 2011, 31, 2080-2089.

13. Zhang, H.F.; Xie, S.L.; Chen, Y.X.; Mai, J.T.; Wang, J.F.; Zhu, W.L.; Zhu, L.G. Altered serum levels of IL-33 in patients with advanced systolic chronic heart failure: correlation with oxidative stress. J. Transl. Med. 2012, 10, 120.

14. Demyanets, S.; Tentzeris, I.; Jarai, R.; Katsaros, K.M.; Farhan, S.; Wonnerth, A.; Weiss, T.W.; Wojta, J.; Speidl, W.S.; Huber, K. An increase of interleukin-33 serum levels after coronary stent implantation is associated with coronary in-stent restenosis. Cytokine 2014, 67, 65-70.

15. Dhillon, O.S.; Narayan, H.K.; Khan, S.Q.; Kelly, D.; Quinn, P.A.; Squire, I.B.; Davies, J.E.; Ng, L.L. Pre-discharge risk stratification in unselected STEMI: Is there a role for ST2 or its natural ligand IL-33 when compared with contemporary risk markers? Int. J. Cardiol. 2013, 167, 2182-2188.

16. Demyanets, S.; Speidl, W.S.; Tentzeris, I.; Jarai, R.; Katsaros, K.M.; Farhan, S.; Krychtiuk, K.A.; Wonnerth, A.; Weiss, T.W.; Huber, K.; et al. Soluble ST2 and interleukin-33 levels in coronary artery disease: Relation to disease activity and adverse outcome. PLoS One 2014, 9, e95055.

17. Seki, K.; Sanada, S.; Kudinova, A.Y.; Steinhauser, M.L.; Handa, V.; Gannon, J.; Lee, R.T. Interleukin-33 prevents apoptosis and improves survival after experimental myocardial infarction through ST2 signaling. Circ. Heart Fail. 2009, 2, 684-691.

18. Dieplinger, B.; Egger, M.; Haltmayer, M.; Kleber, M.E.; Scharnagl, H.; Silbernagel, G.; de Boer, R.A.; Maerz, W.; Mueller, T. Increased soluble ST2 predicts long-term mortality in patients with stable coronary artery disease: Results from the Ludwigshafen risk and cardiovascular health study. Clin. Chem. 2014, 60, 530-540.

19. Wojtczak-Soska, K.; Pietrucha, T.; Sakowicz, A.; Lelonek, M. Soluble ST2 protein in chronic heart failure is independent of traditional factors. Arch. Med. Sci. 2013, 9, 21-26.

20. Tsapaki, A.; Zaravinos, A.; Apostolakis, S.; Voudris, K.; Vogiatzi, K.; Kochiadakis, G.E.; Spandidos, D.A. Genetic variability of the distal promoter of the ST2 gene is associated with angiographic severity of coronary artery disease. J. Thromb. Thrombolysis 2010, 30, 365-371.

21. Yu, J.; Song, J.; Wang, N.; Wu, Z.; Zhang, Q.; Zhang, N.; Zhang, W.; Xuan, S.; Lan, T. Implication of IL-33 gene polymorphism in Chinese patients with Alzheimer's disease. Neurobiol. Aging 2012, 33, 1011-1014.

22. Ryckman, K.K.; Williams, S.M.; Krohn, M.A.; Simhan, H.N. Interaction between interleukin-1 receptor 2 and Toll-like receptor 4, and cervical cytokines. J. Reprod. Immunol. 2011, 90, 220-226. 
23. Kim, J.J.; Hong, Y.M.; Sohn, S.; Jang, G.Y.; Ha, K.S.; Yun, S.W.; Han, M.K.; Lee, K.Y.; Song, M.S.; Lee, H.D.; et al. A genome-wide association analysis reveals $1 \mathrm{p} 31$ and 2p13.3 as susceptibility loci for Kawasaki disease. Hum. Genet. 2011, 129, 487-495.

24. Akhabir, L.; Sandford, A. Genetics of interleukin 1 receptor-like 1 in immune and inflammatory diseases. Curr. Genomics 2010, 11, 591-606.

25. Buysschaert, I.D.; Grulois, V.; Eloy, P.; Jorissen, M.; Rombaux, P.; Bertrand, B.; Collet, S.; Bobic, S.; Vlaminck, S.; Hellings, P.W.; et al. Genetic evidence for a role of IL33 in nasal polyposis. Allergy 2010, 65, 616-622.

26. Menon, R.; Fortunato, S.J.; Edwards, D.R.; Williams, S.M. Association of genetic variants, ethnicity and preterm birth with amniotic fluid cytokine concentrations. Ann. Hum. Genet. 2010, $74,165-183$.

27. Chapuis, J.; Hot, D.; Hansmannel, F.; Kerdraon, O.; Ferreira, S.; Hubans, C.; Maurage, C.; Huot, L.; Bensemain, F.; Laumet, G.; et al. Transcriptomic and genetic studies identify IL-33 as a candidate gene for Alzheimer's disease. Mol. Psychiatry 2009, 14, 1004-1016.

28. Gudbjartsson, D.F.; Bjornsdottir, U.S.; Halapi, E.; Helgadottir, A.; Sulem, P.; Jonsdottir, G.M.; Thorleifsson, G.; Helgadottir, H.; Steinthorsdottir, V.; Stefansson, H.; et al. Sequence variants affecting eosinophil numbers associate with asthma and myocardial infarction. Clin. Exp. Allergy 2008, 38, 1875-1881.

29. Sakashita, M.; Yoshimoto, T.; Hirota, T.; Harada, M.; Okubo, K.; Osawa, Y.; Fujieda, S.; Nakamura, Y.; Yasuda, K.; Nakanishi, K.; et al. Association of serum interleukin-33 level and the interleukin-33 genetic variant with Japanese cedar pollinosis. Clin. Exp. Allergy 2008, 38, 1875-1881.

30. Zheng, S.L.; Liu, W.; Wiklund, F.; Dimitrov, L.; Balter, K.; Sun, J.; Adami, H.O.; Johansson, J.E.; Sun, J.; Chang, B.; et al. A comprehensive association study for genes in inflammation pathway provides support for their roles in prostate cancer risk in the CAPS study. Prostate 2006, 66, 1556-1564.

31. Castano, R.; Bosse, Y.; Endam, L.M.; Desrosiers, M. Evidence of association of interleukin-1 receptor-like 1 gene polymorphisms with chronic rhinosinusitis. Am. J. Rhinol. Allergy 2009, 23, 377-384.

32. Shimizu, M.; Matsuda, A.; Yanagisawa, K.; Hirota, T.; Akahoshi, M.; Inomata, N.; Ebe, K.; Tanaka, K.; Sugiura, H.; Nakashima, K.; et al. Functional SNPs in the distal promoter of the ST2 gene are associated with atopic dermatitis. Hum. Mol. Genet. 2005, 14, 2919-2927.

33. Kim, S.S.; Cheong, J.Y.; Lee, D.; Lee, S.K.; Kim, M.H.; Kwack, K.; Yang, S.J.; Lee, H.Y.; Cho, S.W. Interleukin-1 $\beta$ and interleukin-1 receptor accessory protein gene polymorphisms are associated with persistent hepatitis B virus infection. Hepato-Gastroenterology 2012, 59, 190-197.

34. Ali, M.; Zhang, G.; Thomas, W.R.; McLean, C.J.; Bizzintino, J.A.; Laing, I.A.; Martin, A.C.; Goldblatt, J.; Le Souef, P.N.; Hayden, C.M. Investigations into the role of ST2 in acute asthma in children. Tissue Antigens 2009, 73, 206-212.

35. He, M.; Guo, H.; Yang, X.; Zhou, L.; Zhang, X.; Cheng, L.; Zeng, H.; Hu, F.B.; Tanguay, R.M.; $\mathrm{Wu}, \mathrm{T}$. Genetic variations in HSPA8 gene associated with coronary heart disease risk in a Chinese population. PLoS One 2010, 5, e9684. 
36. Shi, Y.; Zhou, L.; Huang, L.H.; Lian, Y.T.; Zhang, X.M.; Guo, H.; Wu, T.C.; Cheng, L.X.; He, M.A. Plasma ferritin levels, genetic variations in HFE gene, and coronary heart disease in Chinese: A case-control study. Atherosclerosis 2011, 218, 386-390.

37. Rapaport, E. Nomenclature and criteria for diagnosis of ischemic heart disease. Report of the Joint International Society and Federation of Cardiology/World Health Organization task force on standardization of clinical nomenclature. Circulation 1979, 59, 607-609.

38. Savenije, O.E.; Kerkhof, M.; Reijmerink, N.E.; Brunekreef, B.; de Jongste, J.C.; Smit, H.A.; Wijga, A.H.; Postma, D.S.; Koppelman, G.H. Interleukin-1 receptor-like 1 polymorphisms are associated with serum IL1RL1-a, eosinophils, and asthma in childhood. J. Allergy Clin. Immunol. 2011, 127, 750-756.

39. Gauderman, W.J.; Morrison, J.M. Quanto 1.1: A computer program for power and sample size calculations for genetic-Epidemiology studies. Available online: http:/hydra.Usc.Edu/gxe (accessed on 1 December 2008).

(C) 2014 by the authors; licensee MDPI, Basel, Switzerland. This article is an open access article distributed under the terms and conditions of the Creative Commons Attribution license (http://creativecommons.org/licenses/by/4.0/). 